doi: $10.15407 /$ ujpe61.11.1026

\title{
ACADEMICIAN OF THE NATIONAL ACADEMY OF SCIENCES OF UKRAINE MARAT TERENTIYOVYCH SHPAK (to the 90-th anniversary of his birthday)
}

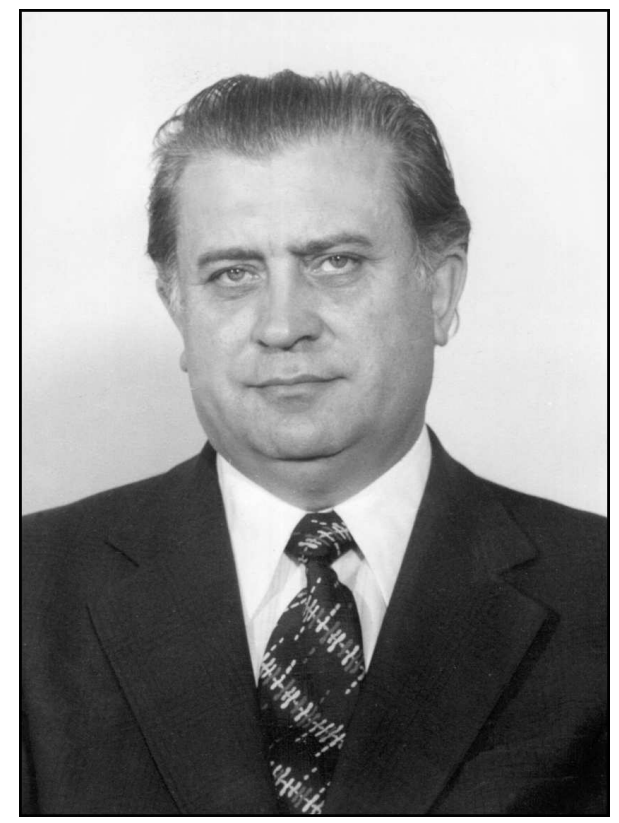

This year, well-known Ukrainian physicist, an expert in solid state physics and quantum electronics, Academician Marat Terentiyovych Shpak would have turned 90 years. He died suddenly, still being full of energy. The whole scientific activity of M.T. Shpak was connected with the Institute of Physics of the National Academy of Sciences of Ukraine. Here, he passed a way from a post-graduate to the Director of the Institute and headed it for 17 years, from 1970 to 1987.

M.T. Shpak was born on April 13, 1926, in the village of Chupakhivka (the Sumy region). In 1943, he finished secondary school in the town of Balakhna (at that time, the Gor'kii region of the USSR), where he had been evacuated at the beginning of the war. In 1946, M.T. Shpak became a student of the Faculty of Physics and Mathematics at the Chernivtsi University. After graduating from the University, he was left at the Chair of Experimental Physics and, in 19511952, worked there as an assistant.

In 1952, M.T. Shpak became a post-graduate of the Institute of Physics of the Academy of Sciences of the UkrSSR (Kyiv). He started his work in the 6-th department of the Institute under the supervision of A.F. Prikhotko.

In 1956, M.T. Shpak defended his Ph.D. thesis "Spectral study of some polycyclic hydrocarbons" and, in 1965, the Dr. Sci. thesis "Experimental study of luminescence of molecular crystals". In 1956-1958, he was a junior research assistant and, in 19581962 , the scientific secretary of the institute. In 1962 1965, he was a senior research assistant. In 1966, M.T. Shpak became the Head of the Photoactivity Department and held this post till 1993. In 19651970, he was the first Deputy Director of the Institute of Physics.

In 1970, the Institute of Physics was reorganized. In particular, on the basis of some of its departments, a new academic institution was created, the Institute for Nuclear Research. M.T. Shpak was appointed the Director of the Institute of Physics of the NAS of Ukraine and headed it for 17 years till 1987. M.T. Shpak's activity at this post was quite successful. During his directorship (1970-1987), a number of important scientific and managerial actions were performed at the Institute, which considerably promoted the growth of the efficiency of fundamental research and application developments. Within this period, the employees of the Institute were awarded

ISSN 2071-0194. Ukr. J. Phys. 2016. Vol. 61, No. 11 
the State Prize of the USSR, nine State Prizes of Ukraine, the Lenin Comsomol Prize, and two Nikolai Ostrovskii republican Comsomol Prizes. The total number of Institute's staff grew from 415 to 650 persons, including Doctors of Sciences from 10 to 37, and Ph.D's from 45 to 158 persons. About 40 monographs were published. The amount of produced liquid helium was more than triplicated. In 1979, in connection with the 50-th anniversary of the foundation of the Institute of Physics, the Institute was awarded the Labor Red Banner order.

It should be noted that Marat Terentiyovych successfully and skillfully combined his long-term managerial activity with the scientific one, which deservedly made him outstanding throughout the world as an expert in physics. The fundamental research carried out by M.T. Shpak and his numerous disciples made considerable contributions to the formation and the development of such scientific areas as solid state physics, low-temperature spectroscopy of condensed state, optical quantum electronics, laser spectroscopy, nonlinear optics, and holography.

The pioneer cycle of M.T. Shpak's works devoted to the luminescence of molecular crystals, which was carried out in the late 1950s and in the early 1960s, became one of the most substantial achievements in solid state physics. For the first time, the excitonic luminescence of molecular crystals was discovered. A scientific direction was created that allowed the mechanism of photoluminescence in crystals, both pure ones and with various impurities and defects, to be developed in detail, and the role of excitons in the processes of energy transport and emission to be elucidated. These studies have made it possible to establish the nature of the emission spectra that were earlier wrongly associated with transitions between the intrinsic energy states of crystals.

Later, the original research led by M.T. Shpak and dealing with the influence of impurities, deformations, and various defects on the physical properties of molecular crystals were widely extended. As a result of this cycle of research, the so-called local excitonic states were discovered in benzene, naphthalene, and anthracene crystals, and their structure and properties were studied. The papers published by M.T. Shpak on this subject became well-known and classical. They were highly appreciated both in our country and abroad.
In the middle of the 1960s, M.T. Shpak began to actively work in a new, at that time, physical domain, quantum electronics and laser spectroscopy. Comprehensive study of nonlinear optical spectral characteristics were carried out for the solutions of a wide class of organic dyes, which allowed the scientists to develop the physical principles of controlling the laser emission frequency and to create a series of tunable-frequency lasers. In 1974, for the cycle of those works, M.T. Shpak together with a group of his colleagues from the IP AS UkrSSR was awarded the State Prize of the UkrSSR.

The team from the Photoactivity Department has also obtained a number of other interesting results in quantum electronics. For the first time, the scientists obtained the light generation by liquid crystals activated by dyes, created a laser with a distributed feedback based on doped liquid crystals, and carried out the temperature tuning of the lasing frequency. Some new nonlinear optical phenomena were detected and studied, such as the superluminescence from the solutions of organic dyes, stimulated Raman scattering with negative absorption, etc.

At the beginning of the 1970s, M.T. Shpak supported works started in a scientific group headed by the Dr. Sci. in Phys. and Math. M.V. Danyleiko. The research was aimed at the study of the physical properties of ring gas lasers with nonlinearly absorbing media. The results of the research played the role of a basis for the development and the fabrication of highly frequency-stable lasers with unique parameters. Lasers of this series were several times awarded the diplomas and the gold medals of the Exhibition of economic achievements of the USSR. They were recommended to be used as secondary frequency standards. Later, in 1986, this group formed the laboratory of laser spectroscopy as a subdivision of the Photoactivity Department. In 2006, owing to the wide development of this field of research, the laboratory was rearranged into two new scientific departments: the Department of Coherent and Quantum Optics headed by Academician of the NASU L.P. Yatsenko and the Department of Laser Spectroscopy headed by Corresponding Member of the NASU A.M. Negryiko.

The results of fundamental research carried out by M.T. Shpak were published in more than 300 scientific works and 2 books: E.A. Tikhonov and M.T. Shpak, Nonlinear Optical Phenomena in Organic Compounds (Naukova Dumka, Kyiv, 1979) (in 
Russian) and N.I. Ostapenko, V.I. Sugakov, and M.T. Shpak, Spectroscopy of Defects in Organic Crystals (Naukova Dumka, Kyiv, 1988) (in Russian) [English translation: N.I. Ostapenko, V.I. Sugakov, and M.T. Shpak, Spectroscopy of Defects in Organic Crystals (Kluwer, Dordrecht, 1993)].

M.T. Shpak has brought up a large group of highly skilled experts in modern physics. Among his disciples, there are about 10 Doctors of Science and more than 30 Ph.D's in Phys. and Math. Many of them successfully work at the scientific and higher educational institutions of Ukraine and abroad.

M.T. Shpak successfully combined the research, managerial, and public activity. For many years, he was the Chairman of the Scientific council of the AS of the UkrSSR on the problem "Quantum electronics", a member of the Scientific council of the AS of the USSR "Luminescence and development of its applications in national economy", a member of the Presidium of the republican division of the Znannya union, and so on. He was Acting Deputy of the Editor-inChief of the Ukrainian Journal of Physics. He was an initiator of the Republican school-seminar "Spectroscopy of molecules and crystals", which later became international and continues to be regularly held biennially till now. In total, 22 school-seminars were organized in different towns of Ukraine in 19732015.

The scientific and managerial activity of M.T.Shpak was highly recognized by both the state and the scientific community. In 1968, he obtained the academic rank of Professor and, in 1986, became the Honored worker of Science and Engineering of Ukraine. In 1969, Marat Terentiyovych was elected Corresponding Member and, in 1990, Academician of the AS of the UkrSSR in the speciality "Experimental physics". In 1976, he was awarded the Labor Red Banner order. In 1986, M.T. Shpak was awarded the second State Prize of the UkrSSR for research, development, and application of the methods and equipment for non-destructive defectoscopy in microelectronics and space technology.

The colleagues, disciples, and friends of Marat Terentiyovych will always remember him as a remarkable, extraordinary person, who immanently embodied a high intellectual capacity, encyclopedic knowledge, and high moral and ethic standards.

\footnotetext{
M.S. BRODYN, A.G. NAUMOVETS, L.P. YATSENKO, A.M. NEGRYIKO, M.S. SOSKIN, M.V. BONDAR, V.I. MELNYK, N.I. OSTAPENKO, T.M. SMIRNOVA, S.G. ODOULOV, I.P. ILCHYSHYN, M.D. KURMEI
} 